\title{
Me echó bilongo... la brujería sexual entre la dominación masculina y la enemistad genérica: dos casos en la Cuba del periodo especial
}

\author{
Me echo bilongo... the sexual witchcraft between male \\ domination and generic enmity: two cases in the Cuba of the \\ special period
}

Liudamys Barbara Sáez Laredo

Recibido: $30 / 09 / 2018$

Aceptado: $12 / 01 / 2020$

\section{RESUMEN}

Este trabajo indaga cómo operó la brujería sexual dentro de las relaciones de poder sexogenéricas a mediados del periodo especial (1990-2000) en Cuba. Desde la metodología cualitativa se analiza la brujería sexual en la sociedad cubana durante la mencionada etapa, usando varios testimonios, obtenidos a través de entrevistas entre ellos el de una santera cubana con cerca de cincuenta años de práctica. La reflexión concluye con que la brujería sexual opera en tres sentidos fundamentales: primero, como arma ante la dominación masculina que compensa el cambiante equilibrio de poder entre los sexos dentro de la relación marital, sobre la base de las costumbres y las leyes del orden social; segundo, integra las relaciones de poder entre mujeres evidenciando una enemistad genérica femenina; y tercero crea jerarquías sexuales y sociales que se entrecruzan con otras categorías naturalizadas de desigualdad.

Palabras clave: género, sexualidad, brujería sexual, enemistad genérica, dominación, Cuba, periodo especial.

\section{ABSTRACT}

This work explores how sexual witchcraft operated within gender-power power relations in the middle of the special period (1990-2000) in Cuba. From the qualitative methodology, sexual witchcraft in Cuban society is analyzed during the mentioned stage, using several testimonies, among them the one of a Cuban santera with about fifty years of practice. The reflection concludes that sexual witchcraft operates in three fundamental senses: first, as a weapon against male domination that compensates for the changing balance of power between the sexes within the marital relationship, based on customs and the laws of social order; second, it integrates the power relations between women

Liudamys Barbara Sáez Laredo es miembro de la Facultad Latinoamericana de Ciencias Sociales (Ecuador). Correo electrónico: 1saez871202@gmail.com. ID: http:/ / orcid.org/0000-0003-0581-7020

Cómo citar este artículo: Sáez Laredo, L. B. (2019). Me echó bilongo...la brujería sexual entre la dominación y la enemistad genérica: dos casos en la Cuba del periodo especial. Atlánticas. Revista Internacional de Estudios Feministas, 4 (1), 358-385. doi: http: / / dx.doi.org/10.17979/arief.2019.4.1.4365 
evidencing a feminine generic enmity; and third, it creates sexual and social hierarchies that intersect with other naturalized categories of inequality.

Keywords: gender, sexuality, sexual witchcraft, generic enmity, domination, Cuba, special period. 


\section{INTRODUCCIÓN}

Desde la radio, se escucha la popular melodía: "esa negra santa camará, que me echó bilongo..." y le sigue otra, también muy conocida dentro de la música cubana: "me está bajando un calor/ de la cabeza a los pies/ por aquella burundanga/ que pusiste en el café..." Y es que el bilongo, la burundanga ${ }^{1}$ o la brujería sexual devienen motivo de inspiración en varias interpretaciones populares en Cuba a largo de las generaciones. ¿Qué implica pensar en la brujería sexual desde una perspectiva sociológica?

Hablar de brujería sexual parecería asunto de épocas coloniales. Sin embargo, en Cuba ha sido, y sigue siendo, un fenómeno que da cuenta de las interacciones y relaciones de poder en el ámbito de la sexualidad. Ambrosia Agramonte, santera de casi cincuenta años de práctica, me relató en reiteradas ocasiones la afición y/o creencia de "la gente, hombres y mujeres, blancos y negros... por estas cosas" como una característica idiosincrática dentro de lo cubano.

La brujería sexual alude a aquellos rituales, brebajes y/o conjuros (amarres, ${ }^{2}$ por ejemplo) que inciden en el deseo sexual, y otorgan cierto poder simbólico -a la manera de Bourdieu (2000)- en las relaciones. Tales prácticas son ejecutadas por santeros y santeras, espiritistas y paleros ${ }^{3} .$. a partir de su alta demanda y costo en el mercado de la religiosidad popular cubana. Así se introduce un tercero en la relación conyugal o sexual, para mediar con "poderes sobrenaturales" en favor de quien solicita su oficio, ya sea para hechizar o curar.

\footnotetext{
Los términos burundanga y bilongo han sido tradicionalmente usados en Cuba para referirse a la práctica de los hechizos sexuales.

"Amarrar, según el Diccionario del español de Cuba, es también "lograr mediante trabajos de santería el amor o el favor de una persona" (Cárdenas y Tristá, 2000, p. 26).

${ }_{3}$ Practicantes de la regla de Palo Monte, dentro de la religiosidad afrocubana.
} 
El empleo y la creencia de las mujeres en este tipo de encantamientos sobre los hombres tienen el fin de dominarlos para obtener recursos materiales, defenderse de la violencia o atraer su atención. No obstante, hablar solo de esta dimensión invisibilizaría otra parte, en mi opinión, fundamental para entender cómo opera la brujería sexual en las relaciones sociales en Cuba. En tal sentido, vale la pena hablar de las competencias y/o disputas que entre mujeres se observan a partir de este fenómeno.

¿Cómo operó la brujería sexual dentro de las relaciones de poder sexogenéricas a mediados del periodo especial (1990-2000) en la localidad de Mayajigua, al centro norte de Cuba? Este trabajo tiene el objetivo de analizar la brujería sexual en la sociedad cubana durante esta etapa como parte de la lucha por revertir la dominación masculina, pero además como expresión de la enemistad genérica entre mujeres, así como su interconexión con la estratificación sexual y social. Al tiempo, se problematiza la naturalización del uso de tales prácticas entre mujeres negras para informar, de modo más amplio, la forma en que el sincretismo y la transculturación atraviesan la religiosidad del pueblo cubano trascendiendo género, raza, clase, edad...

Vale aclarar que la enemistad genérica comprende la anulación de lo común entre mujeres primando lo que las separa -clase, raza, edad, relación con los hombres, belleza, autoridad...-. De ese modo, ocurren disputas por espacios de supervivencia, más allá de redes o alianzas solidarias (Lagarde, 2012, 2005, 1992).

El trabajo se centra en dos casos acaecidos entre 1995 y 1996, en Mayajigua, poblado del centro norte de Cuba. El primero presenta la curación de un hombre víctima de hechizos sexuales por parte de su esposa a través de la 
ingesta de ciertas "sustancias tóxicas"; y evidencia las tensiones entre esposa y suegra. El segundo caso se centra en las disputas de dos jineteras, ${ }^{4}$ que eran primas y compañeras en un espacio de trabajo, pero que llegan al punto de atentar contra sus integridades físicas.

Los relatos llegan desde las memorias de mi bisabuela, Ambrosia Agramonte, una santera cubana quien curó a varios hombres de estos hechizos sexuales. Del mismo modo, actuó como consejera en varias rencillas entre mujeres, que no dan cuenta de redes de solidaridad como indican otros trabajos sobre brujería sexual (Behar 1993), sino de una enemistad fijada entre esposas y amantes, suegras y nueras, cuñadas, primas, amigas...

La entrevista fundamental, en la cual se basa este trabajo, la hice a mi bisabuela en 2008 como parte de un ejercicio investigativo de la carrera de Periodismo. Posteriormente, continúe las conversaciones a fin de realizar un documental radial, pero fueron las valiosas notas off record que tomé acerca de los aspectos cotidianos las más reveladoras para desarrollar las reflexiones que aquí presento.

Seleccioné los casos de estudio con base en el testimonio de mi bisabuela y el registro de ahijados y consultantes de los años 1995-1996 -único que se conservaba-. Este patrimonio familiar, que contenía la escritura de mi bisabuela y de otros familiares que, como yo, servimos de escribas durante sus consultas, es también evidencia empírica de la realidad social cubana. Los datos, que con tanto recelo guardó, informan de los nombres, motivos, profesión, si asistían solos/as o con sus familiares, y hasta de los precios que

${ }^{4}$ Calificativo popular para las trabajadoras sexuales surgido en Cuba durante el periodo especial; en lo adelante utilizo este término. 
llevaron a cientos de consultantes a acudir a mi bisabuela a mediados del periodo especial en Cuba.

Contacté con algunos/as informantes durante mi viaje al archipiélago en 2017, pero en esa oportunidad no pude entrevistarles. Ya fuera del país, recurrí a chats por Facebook, videollamadas y contactos telefónicos para conversar con quienes consintieron ofrecer sus entrevistas a fin de incluirlas en mi investigación de maestría. Así obtuve los testimonios de otros/as pobladores/as partícipes en los casos -el hombre curado, su exsuegra y una de las jineteras ${ }^{5}$-.

En concordancia con la práctica de mi bisabuela de proteger los nombres de quienes consultaba, y respetando la solicitud de las tres personas entrevistadas, se han ocultado bajo seudónimos las verdaderas identidades de los/las informantes y protagonistas del caso, solo el nombre de mi bisabuela es real. En la tabla 1, se detallan las fechas y circunstancias de las entrevistas realizadas.

Tabla 1. Datos de las entrevistas realizadas

\begin{tabular}{|l|l|l|}
\hline $\begin{array}{l}\text { Entrevistada/o } \\
\text { (identificación) }\end{array}$ & $\begin{array}{l}\text { Fecha de la entrevista o } \\
\text { conversación }\end{array}$ & Forma de entrevista \\
\hline $\begin{array}{l}\text { Ambrosia Agramonte } \\
\text { (santera) }\end{array}$ & 2008 & Cara a cara \\
\hline Myriam (exjinetera) & julio de 2017 & $\begin{array}{l}\text { Conversación por chat } \\
\text { (Facebook) }\end{array}$ \\
\hline José (hombre curado) & julio de 2017 & Videollamada \\
\hline $\begin{array}{l}\text { Marisela (exsuegra del } \\
\text { hombre curado }\end{array}$ & julio de 2017 & Llamada telefónica \\
\hline
\end{tabular}

Hay que llamar la atención sobre la etapa histórica en que se enmarcan los casos: el periodo especial (1990-2000). Por un lado, es esta una etapa de 
profunda crisis económica atravesada por la incidencia de cambios estructurales y factores externos (el bloqueo económico), y donde la población busca ante todo sobrevivir. Por otro, coincidiendo con Bolívar (1997) ocurre una apertura a las prácticas religiosas, en especial hacia los cultos de origen afrocubano, que facilitó el acceso y la comercialización de estas formas de religiosidad como armas simbólicas ante la precaria situación.

El análisis se ha dispuesto en dos ejes principales de discusión, pero antes se ubica, a manera de antecedentes, un epígrafe que apunta algunos rasgos del periodo especial, las relaciones sexogenéricas y la brujería sexual. En el primer eje, se analiza la brujería sexual como arma ante la dominación masculina medida a partir de la virilidad, la economía de los bienes simbólicos y la asimilación de la dominación (Bourdieu, 2000); tal análisis se articula con la noción del cambiante equilibrio de poder entre los sexos (Elias, 1994).

Mientras, el segundo eje se concentra en desentramar las relaciones de poder sexogenéricas entre mujeres, en discusión con el propio Bourdieu (2000), Gayle Rubin (1989) y Marcela Lagarde (1992). En este particular entran como subcategorías de análisis las relaciones de parentesco y la enemistad genérica femenina con base en la sexualidad. De manera general, el argumento se nutre de las teorías de Stolcke (2000) sobre la naturalización de la desigualdad ${ }^{6}$ y la estratificación sexual de Rubin (1989).

En este sentido, metodológicamente tomo el recaudo que plantea Stolcke para analizar los "sistemas de clasificación y de descalificación" (2000, p. 53) sociales, quien sugiere examinar en detalle los argumentos, categorizaciones y contextos

\footnotetext{
" Entendida como la asimilación ideológica sobre la diferenciación y la jerarquización social con base en los rasgos "naturales"-sexo y raza-, aspectos que impiden el ascenso social en una sociedad que iguala las oportunidades (Stolcke 2000), como la socialista, por ejemplo [aunque Stolcke habla de sociedades de clases sus aportes pueden aplicarse al estudio de la sociedad cubana entre 1990-2000].
} 
particulares que generan desigualdad. Ello también exige el uso correcto del concepto naturalización, no como una repetición aprehendida, sino como una discriminación sobre la base de rasgos "naturales". Del mismo modo parto de la propuesta sociológica de Elias (1994) sobre analizar los sucesos del pasado con énfasis en las particularidades contextuales.

Por último, quisiera explicar dos aspectos éticos del trabajo desarrollado. Primero, reproduzco fielmente los testimonios tanto de la santera como de los entrevistados/as, así que como integrantes de un sector popular a veces incluyen vulgarismos, ${ }^{7}$ pero me he permitido ubicarlos para no truncar la riqueza testimonial. Segundo, he omitido lo que los informantes me han pedido no revelar acatando con respeto su decisión, en tanto no constituye material únicamente relevante para abordar el objeto de estudio.

\section{APUNTES PARA UNA BIOGRAFÍA SOBRE LA BRUJERÍA SEXUAL Y EL PERIODO ESPECIAL EN CUBA}

La etapa denominada con ironía periodo especial en Cuba, pues de especial no tenía nada más que las dificultades que enfrentaba la gente para sobrevivir, se ubica entre 1990 y el 2000 (Banco Central de Cuba, s. f.); para otros estudiosos se extiende hasta la actualidad (Pérez-López \& Murillo, 2003; Espina et al., 2011; Sklodowska, (2016). En este acercamiento analítico, se toma la primera periodización. A continuación, presento algunas de las características que permiten comprender la inserción de la brujería sexual en este periodo, y cómo en la crisis confluyeron en forma constitutiva lo económico y lo social; me detengo particularmente en sus efectos sobre las relaciones de sexo/género.

Ofrezco disculpas de antemano por algunas frases y palabras que pudieran resultar vulgares. 
Tras la desaparición del campo socialista, y con el recrudecimiento del bloqueo económico por parte de Estados Unidos en la década de los 90, en Cuba se comenzó a vivir una total escasez que impactó de forma severa en la cotidianidad. Este periodo se caracterizó por el shock de la crisis en la materialidad de los cubanos y cubanas.

Para dar una dimensión de la crisis, debo explicar que la gente carecía de detergente, jabón, pasta dental, mucho menos tenía champú o acondicionador, y peor si se trataba del papel higiénico que ya había sido sustituido por el papel periódico. Asimismo, las farmacias eran un lugar simbólico porque no había medicamentos más allá de los jarabes o ungüentos naturales; el transporte apenas existía y para todo se dependía de la bicicleta o un coche de caballos, pues no había combustible.

La electricidad se ausentaba la mayor parte del día, y el apagón (desconexión de las redes de electricidad por extensos horarios) se volvió una cotidianidad más en la vida del cubano y la cubana que por demás no conseguía ni ropas, ni zapatos, ni toallas ni sábanas o fundas. Y lo peor: no había comida, ¿acaso podría perdurar la vida? Al shock de la crisis en la materialidad se sumaron varias medidas por parte del Estado que, en lugar de apalear las dificultades, se convertían en sucesivas formas de desigualdad.

Por ejemplo, la despenalización del dólar o la ampliación del trabajo por cuenta propia favorecían a un grupo de personas que contaban con vínculos en el extranjero, cuyas remesas podían utilizar en estos negocios. El desarrollo del turismo ofrecía puestos de trabajo, pero en estos, la población negra resultó relegada por causa de "la buena presencia" o el "nivel cultural" acelerando las 
desiguales y tensiones raciales que parecían dormidas por años (De la Fuente, 2001).

Se configuraron entonces ciertas vías de escape desde el sector popular como paliativos ante la crisis. Entre estas, el éxodo desesperado hacia los Estados Unidos conocido como el fenómeno de los balseros, y la migración entre provincias hacia la capital. Proliferó el jineterismo como opción de trabajo joven tanto femenino como masculino, pero más marcado en las mujeres. También se acrecentó el comercio de las religiones afrocubanas.

Los trabajos de Basail y Castañeda (1999); Espina (2008, 1997), y Bolívar (1997) informan que la tensión crisis/reformas/modos de supervivencia en relación con la religiosidad popular afrocubana constituye un fenómeno estructural, y no de coyuntura, cuya configuración puede rastrearse en Cuba desde los años 80. La propia Espina (2008) detalla las múltiples ramificaciones del fenómeno cuando agrupa aspectos como los ingresos no asociados a fuentes de trabajo estatal y la legitimación social de la ilegalidad. De modo que algunas formas de religiosidad afrocubanas junto al jineterismo y otras actividades, integraron el listado de productos de la llamada economía sumergida cubana.

A ello se suma la ampliación de las desigualdades económicas racializadas y el énfasis en el blanqueamiento social y económico. En tal sentido los sectores populares, aunque fueron protagonistas, resultaron los mayores perjudicados. Retomo entonces aquel cuestionamiento de Stolcke sobre la naturalización de las desigualdades:

¿cómo se explica que en una sociedad meritocrática supuestamente integrada por sujetos libres de forjar su propio destino persistiese como una especie de reserva ideológica esa "naturalización" de la condición social, siempre disponible para 
racionalizar, en momentos de crisis social, la interiorización y discriminación de los sectores no privilegiados? (Stolcke, 2000, p. 45).

Se puede señalar que la sociedad cubana, tras el triunfo revolucionario de 1959, inició un proceso de desnaturalización de la desigualdad. ¿En qué sentido?, en torno a la noción de igualdad de oportunidades educativas y la asimilación de que género y raza son constructos sociales. La familia, la escuela y la generación como agentes socializadores jugaron un papel esencial en tales procesos desde el cambio estructural experimentado.

También, y siguiendo a Elias (1994), se dio desde el Estado -desde la orientación de la igualdad socialista- y dentro de un proceso de tipo civilizatorio cierto equilibrio de poder en las relaciones maritales. Muchas mujeres que se separaban exigían, aun sin que mediara contrato legal, la mitad de los bienes, evidencia de las transformaciones en las costumbres sociales. Hay que señalar que el matrimonio como institución fue perdiendo terreno ya que proliferaban las uniones libres o relaciones informales (Safa, 2012; Oficina Nacional de Estadística e Información (ONE), 2010).

Sin embargo, ante la interrogante de Stolcke (2000) también se podría argumentar que, en Cuba, un país donde las diferencias de clase se fueron borrando del discurso y del imaginario, pues en realidad persistían en lo microsocial, la estratificación sexual mantenía las jerarquías sociales en correlación con la raza. Así, en lo más bajo de la escala (Rubin, 1989) se ubicaba a los homosexuales, las jineteras -por lo general mulatas o negras- y las mujeres infieles o "ligeras", -la promiscuidad en los hombres se considerada "natural"-, así como quienes practicaban la brujería sexual. 
Myriam, recuerda que como era jinetera, aunque tenía dinero no podía entrar a los hoteles, "no te dejaban ni acercar, y más si eras mulata o negra, ya te tomaban por jinetera y hasta ibas presa". Según la santera Ambrosia Agramonte:

había tanta miseria, que ni con dinero se conseguían las cosas, lo mismo blancos que negros el hambre era pa' to' el mundo; a la gente lo único que le quedaba era su decencia, y hasta eso poco a poco se fue perdiendo.

Durante la crisis se vio favorecida la apertura religiosa: en 1991 con el IV Congreso del Partido Comunista de Cuba se eliminaron las restricciones para que los religiosos integren las filas de la organización; y en 1992, con la reforma constitucional el Estado cubano transformó su declaración "de ateo a laico" (Constitución de Cuba, 1992). De ese modo, se inicia un proceso para dejar atrás el ocultamiento de las prácticas y creencias religiosas, y en especial las de las religiones afrocubanas.

Mientras, en el orden de género persistían mitos como el del hombre proveedor, y la dependencia económica de las mujeres, lo cual no puede leerse solo dentro de la dominación masculina, sino como una estrategia femenina para subsistir en la crisis. Asimismo, resurgió, desde el jineterismo, una estrategia que remite a los periodos colonial y neocolonial cubanos: el matrimonio o la unión informal -en términos legales: unión de hecho-como vía de movilidad en los estratos sociales.

En ese contexto, el análisis de la brujería sexual se enlaza con formas de trabajo dentro del mercado [informal] y con la estratificación social en la Cuba del periodo especial; permite visibilizar información no recogida en datos oficiales, 
por ejemplo: el comercio de la religiosidad afrocubana, el jineterismo y las jerarquías sexuales. Asimismo, con tal análisis se informa del repliegue del proyecto social cubano a las aspiraciones individuales (Espina, 2008) y se evidencian las estrategias personales y familiares de supervivencia.

En resumen, por una parte, ocurre durante esta etapa la correlación crisisreformas estatales y sus impactos en la cotidianidad y las estructuras microsociales (unión marital o libre, y familia). Por otra, y al interior de estas, la brujería sexual integra las relaciones sexogenéricas como arma simbólica ante la dominación masculina y dentro de las relaciones de poder entre mujeres. Tales aspectos se analizan a continuación enmarcados en los años 1995 y 1996, cuando la crisis había alcanzado un punto prominente.

\section{LA BRUJERÍA SEXUAL Y LA DOMINACIÓN MASCULINA}

María Cristina me quiere gobernar y yo le sigo le sigo la corriente, porque no quiero que diga la gentel que María Cristina me quiere gobernar.

(Canción popular cubana)

La María Cristina de nuestro relato se consideraba, según cuenta la santera Ambrosia Agramonte, una mujer afortunada en Mayajigua en el contexto del periodo especial. Aunque dependía de su marido económicamente, para ella esto no representaba problema alguno, ya que como expresaba "tengo un hombre que me mantiene, por eso no trabajo, y además en mi casa soy yo la que lleva los pantalones". Por su parte, según rememoró la santera, José, el marido, sentía cierto malestar al no poder llevar las riendas de la casa. Ese malestar lo llevó a acercarse cautelosamente para tratar "un mal" que le aquejaba. 
El relato de Agramonte (2008) inicia cuando recuenta que María Cristina conversaba con amigas y familiares sobre sus efectivas técnicas ante el "inevitable" dominio de los hombres. Incluso la santera un día le jaraneó: “fulana, el buey manso, un día faja, y así le contestó ella, 'no que va... yo tengo bien manso al buey'". Y es que esa es una de las funciones de la brujería sexual "amansar" a los hombres ante su "ineludible" carácter dominante, y con mayor énfasis, en las relaciones que incluyen violencia o donde la mujer asume una relación extramarital, como era el caso de María Cristina.

Poco a poco José, el marido, se fue acercando para llegar a la santera. Cada día en la tarde a su regreso de las labores de campo, le decía: “'¿Ambrosia cómo está?', y ella pensaba 'este huevo quiere sal: o a qué viene tanta saludadera', y empezó un buen día a traerme un litro de leche cada tarde, y yo lo cogía, nos hacía falta figúrate, y hasta que un día, ya casi oscureciendo, me habló claro: 'Ambrosia necesito que usted me consulte'".

La consulta espiritual funciona más o menos como una consulta médica, un breve diagnóstico, una evaluación del problema y luego se procede a orientar los remedios. De acuerdo con la descripción de la santera ante la pregunta "'qué le pasa hijo, qué se siente', él respondió: 'qué pena decirle Ambrosia, pero me siento flojo sin ganas... de usted sabe... de aquello, ${ }^{8}$ y además me he puesto muy mal del estómago'". Es aquí donde difieren la consulta espiritual y la médica; le toca al espiritista, reconstruir con base en la adivinación de dónde proviene el "mal".

"El mal" que aquejaba a José era el cuestionamiento de su virilidad, "entendida como la capacidad reproductora, sexual y social" (Bourdieu, 2000, p. 68), pero

Se refiere al acto sexual. 
que como explica el propio Bourdieu también representa una carga en tanto se ve disminuida si el hombre no resulta un buen procreador, violento o vengativo con la mujer y el amante. A pesar de los años trascurridos, José recuerda los hechos aún con cierta vergüenza:

No es fácil hablar de eso, uno está viejo, pero todavía pica... lo que sí recuerdo es que la viejita Ambrosia me dio un cocimiento de ajo, no sé que otra cosa, en ayuna tres días para vomitar lo que me habian dado. Me fui a su casa casi de madrugá pa' que nadie me viera, imagínese que lo vieran a uno haciendo brujería, un hombre haciendo brujería, yo era pa' curarme, pero igual la gente habla...

Aparece aquí la virilidad como "concepto eminentemente relacional; construido ante y para los restantes hombres y contra la feminidad" (Bourdieu, 2000, p. 69). Este concepto incluye "la relación sexual como una relación social de dominación" fundamentada en la diferenciación masculino-activo/femeninopasivo; ello supone una organización del deseo y de los roles dentro de la intimidad de la pareja que marca los puntos de dominador-masculino y dominado-femenino (Bourdieu, 2000).

Ahora bien, cuando esta relación aparece invertida ocurre lo problemático pues se desautoriza un modo de dominación que se ha venido construyendo socialmente. Se trata de unos discursos, prácticas y formas de actuar sustentados en la tradición, desde el parentesco, e incrustados en el orden social predominante (Bourdieu, 2000; Stolcke, 2000; Elias, 1994; Rubin, 1989).

Mujeres como María Cristina vieron en la brujería sexual un arma contra la dominación masculina disminuyendo lo que pudiera considerarse, según Bourdieu (2000), una manifestación legítima de la virilidad: la procreación. Tal 
aspecto, Stolcke (2000) lo integra a un sistema de valores atravesado por criterios biológicos que exigen tanto a hombres como a mujeres, perpetuar la existencia humana a través de la reproducción. Al decir de Marisela, la madre de María Cristina:

Yo le dije, hija, algo hay que hacer porque con esta necesidad, no puedes llenarte de muchachos, entonces corrimos pa' Sagua, y ahí dimos con este palero buenísimo que le preparó pa' que no se preñara... a José se le dio en café, así que cada mes decíamos que iba acompañarme al médico y ya tú sabe, íbamos pa'l curandero. ¿Con que pagábamos?, con el mismo dinero que le daba el marido. Pero aquí el que no corre vuela, la vieja [se refiere a la madre de José] también era tremenda, corrió pa' casa de la difunta Ambrosia y se enteraron, y ahí se armó la cagazón.

Vale la pena repensar la aseveración de Bourdieu (2000) sobre la brujería como arma de los débiles [en su análisis la magia], desde el presente caso, pues lo que se observa es cierto acto de resistencia que remite al cambiante equilibrio de poder entre los sexos. Si bien denota un poder simbólico de la mujer, se incorpora un dominio de esta sobre la posibilidad de procreación que viene a equiparar la potencialidad/ deseo de reproducción. En otro sentido, también “el amarre" le aseguraba un sustento económico sin trabajar.

La santera Ambrosia Agramonte explica que muchas de las mujeres que acudían a la brujería sexual también lo hacían para salir embarazadas y de esta forma "amarrar" a los maridos, por medio de la paternidad. Otras que se interesaban en tales prácticas aun no eran víctimas de violencia, o en mi interpretación, sujetos de dominación, sino que iban para prevenir tal dominio; prueba de que esta estructura marital de dominación había sido aprehendida de 
antemano. La metáfora del buey usada por la propia santera, -“el manso un día faja" - también remite a este proceso de la dominación que implica violencia.

Aquí se pone de relieve la asimilación de la dominación. Este proceso ocurre cuando los dominados reproducen y articulan los esquemas de dominación en sus formas de actuar y pensar según las propias relaciones de dominación impuestas, y se presentan a los efectos como sumisos o proclives al sometimiento (Bourdieu, 2000). Tanto las madres, como la mujer, la santera, y el propio José, evidencian tal asimilación.

Analizados los puntos sobre la virilidad y la asimilación de la dominación, conviene revisar lo que Bourdieu (2000) denomina la economía de los bienes simbólicos cuyo mercado es el matrimonio, considerado además la base del orden social. Si bien este autor explica que la mujer deviene objeto dentro de esta economía, ya que pasa a integrar el capital simbólico de los hombres dentro de los sistemas de parentesco, desestima el rol dominante de otras mujeres y las relaciones que se pueden tejer entre estas a partir de las jerarquías -como la relación suegra-nuera o suegra-suegra-. En esa línea, los mandatos sexuales se entrecruzan con los órdenes de género, raza y clase.

A mame $e^{9}$ le importaba que fuera pobre, china, negra, rubia o mulata, la cosa es que fuera una mujer decente, de la casa, por eso se sintió tan mal, era una falta de respeto... y $\mathrm{pa}^{\prime}$ colmo ella y la madre eran brujeras (José 2017, entrevista en videollamada).

Como se puede ver, aunque se desestiman los componentes clasistas y de raza, lo sexual se prefigura como el elemento que desde la jerarquía de suegra valora el ingreso o no al parentesco. Así es que, por extensión, algunas mujeres como

-Vocablo popular que alude a la madre. 
María Cristina también usaban este tipo de encantamientos para "amansar" a las suegras previniendo otras réplicas de la dominación. A propósito, ¿cómo la brujería sexual estructura estas relaciones de poder entre mujeres?; a ese particular se dedica la discusión que sigue.

\title{
4. JINETERAS EN DISPUTA: LA BRUJERÍA SEXUAL Y LAS RELACIONES DE PODER ENTRE MUJERES
}

\author{
Como dice Jorge Amado hermana prostibularia \\ /tengan conciencia de clase/ sean putas proletarias \\ (Embajadora del sexo, Frank Delgado)
}

Como bien explica Rubin, “aunque su contenido varía, el formato de una única norma sexual se reconstituye continuamente en otros marcos retóricos, incluidos el feminismo y el socialismo" (1989, p. 23). En Cuba, la persecución que sufrieron las jineteras solo se compara con la lucha cruenta que se llevó a cabo contra la homosexualidad en las décadas de los 70 y los 80 -no me detengo en tal aspecto pues no es objeto de la investigación-. Sin embargo, en tal contexto se puso de manifiesto en este gremio, por encima de solidaridades y ayudas, la enemistad genérica entre mujeres (Lagarde 2012, 2005, 1992).

Si bien se tejieron redes para apoyar la migración sexual, que como expone Rubin (1989), consiste en una de las estrategias en las que se apoyan las personas sexualmente degradadas, no se llegó a construir entre las jineteras un marco de sororidad, contrario a lo que propone Lagarde (2012), quien argumenta que las mujeres deben apostar por esas uniones estratégicas en 
espacios de opresión. Myriam, originaria de Mayajigua, cuenta cómo le fue en Ciudad de la Habana, en aquel entonces capital de Cuba, en el año 1992:

Imagínate que yo no cogí carrera, no pude entrar a la universidad, y entonces me fui en casa de mi tía allá en La Lisa, y con otras primas nos pusimos a luchar ${ }^{10}$, tú sabes, ella decía "hay que aportarla porque si no ya saben..." (...) ahora no me da tanta pena contarlo, pero eso fue de pinga en realidad todas pensábamos buscar un "temba que nos mantenga", un yuma ${ }^{11}$ claro: italiano, español, mexicano, bueno, de donde fuera (ja, ja, ja), casarnos y ya, y si era joven mejor, pero ya ves en la calle pasan los días, los meses, los años y na' te pudres ahí... Al principio, los primeros años tenías que decirle al yuma oye cómprame tal cosa, unas zapatillas, un pitusa, lo que fuera, no podías andar con dólares porque te cargaba la fiana, ${ }^{12}$ ¡imagínate si se daban cuenta de que eras jinetera! Aparte, las mismas jineteras te echaban pa'lante con la policía, algunas eran chivatas ${ }^{13} \ldots$

La persecución policial fue una de las prácticas de criminalización del trabajo sexual que muchas veces iniciaba bajo la sospecha de posesión ilegal de divisas. Aunque en 1993 se despenalizó la tenencia de dólares, los precios de esta moneda rodaban como recuerda Myriam "los 150 pesos, y no había nada que comprar", y en La Habana las persecuciones aumentaron. El jineterismo se convirtió en un problema no solo sexual sino social que originó "un nuevo sistema sexual caracterizado por tipos distintos de personas, poblaciones, estratificación y conflictos político-sexuales" (Rubin, 1989, p. 25).

Entonces viramos pa' Mayajigua, y mi prima Tania conmigo. Al principio imagínate yo no quería que empezáramos a "trabajar", pero en eso llega un extranjero por aquí, un italiano que dice que hace fotos de mujeres negras, y

\footnotetext{
${ }^{10}$ Este verbo agrupa, en el léxico popular, las formas de ilegalidad socialmente aceptadas.

"Frase coloquial que se refiere a los extranjeros/as que visitan la isla.

La policía.

Apelativo peyorativo para denominar a los/las informantes de la Policía Nacional Revolucionaria (PNR).
} 
yo le caí en gracia al yuma... De ahí me invita a $\operatorname{Los}_{\operatorname{lagos}}{ }^{14}$ y tú sabes yo dije al fin salí de este trabajo y de esta miseria: mujer de yuma y a vivir tranquila.

Coincido con Rubin (1989) cuando expresa que, si bien se establecen rigurosas restricciones legales sobre el sexo, las más fuertes se dan en el control y señalamiento social que les toca vivir a las personas sexualmente "inferiores". Desde el discurso político cubano a las jineteras se les catalogó como el retorno a los males sociales del capitalismo. En lo cotidiano social se volvía a las nociones de honor, y las propias mujeres descalificaban a las jineteras en los escenarios del espacio público.

Myriam relata cómo se perdían las amigas, y solo te quedaban como compañeras las mismas jineteras, "pero en ellas no se podía confiar". La propia santera valoraba con recelo tal actividad, aunque en varias ocasiones le salió al paso a algunas mujeres que en espacios de sociabilidad femenina tendían a discriminarlas: "cada cual hace de su culo un tambor y se lo da tocar a quien quiera; en eso no hay que meterse". En tanto los hombres se la pasaban acosándolas al tildarlas de "mujeres fáciles".

El control social desde la religión y la religiosidad en Cuba obedece al propio fenómeno del sincretismo y la transculturación, en términos de Ortiz (1940). De ese modo, y como explica Rubin (1989), desde lo católico, se imponían unos valores que responden al matrimonio para toda la vida, la fidelidad, entre otras nociones a las que también se acogían los testigos de Jehová. En cambio, para las religiones afrocubanas, en tanto no cuentan con tales principios en su cuerpo

\footnotetext{
${ }^{14}$ Centro turístico San José del Lago, ubicado en Mayajigua.
} 
mítico, ético y ritual, la libertad sexual no significaba problema alguno y menos practicar la brujería sexual -que además le resultaba un buen negocio-.

En tal sentido, vale la pena explicar que la brujería sexual toma aquí otras dimensiones más allá de lucha contra la dominación masculina. ${ }^{15}$ Primero, funciona como un elemento para incrementar el atractivo sexual por parte de las mujeres. Segundo, se aplicaba también este poder de seducción a los policías y otros oficiales para evitar problemas con la ley. Por último, y como más novedoso, se refiere a las relaciones de poder, entre las trabajadoras de un mismo gremio que ponían por encima de todo el triunfo individual relegando cualquier tipo de conexión -amistad o parentesco- a un segundo plano; es en este punto donde me detengo más detalladamente.

Lo primero tiene que ver con la inversión de una idea planteada por Bourdieu (2000) al interior de la relación sexual: "el placer masculino es (...) disfrute del placer femenino, del poder de hacer disfrutar" (p. 34). Aquí el placer y mérito de la jinetera estaba, como cuenta Myriam, en la capacidad que tenían de hacer disfrutar a los hombres, a los extranjeros "que venían huyendo de sus mujeres viejas, porque muchos eran casados, y querían gozar, eso querían... y te recomendaban con otros, o volvían a buscarte".

El segundo aspecto, según relató la santera Ambrosia Agramonte, se concretaba en frases como "Ambrosia hágame algo para que no me coja la policía". Entonces, además de los baños con canela y miel, se efectuaban otras maniobras para evitar la detención policial. La brujería sexual entraba a reducir el accionar

\footnotetext{
${ }^{15}$ Aquí no se aborda la relación jineteras-proxeneta [chulo], ya que, en este caso según Myrian, ellas actuaban sin mediadores masculinos. Ello podría motivar otros análisis de la dominación masculina.
} 
de los agentes que muchas veces se hacían "los de la vista gorda" y no las detenían. En otras ocasiones las dejaban ir con la promesa de reencontrarse en próximos intercambios sexuales.

Siguiendo la historia de Myriam se entra de lleno en los artificios de la brujería sexual en las relaciones de poder sexogenéricas entre mujeres. Competían para llevarse, en voz de Myriam:

el mejor yuma al agua; y ahí te hacían de todo: te daban bebidas con polvos para que te enfermes del interior, les daban tu nombre a los brujeros para que te tiren cosas y no puedas salir a trabajar. Lo de mi prima fue lo peor, y por eso me dolió tanto, era el cuento que te hice del yuma fotógrafo de Los Lagos, imagínate que cuando la tipa vio que el yuma estaba pa' mí, me robó un blúmer de la tendedera, y se lo llevó a un brujero para que me jodiera, eran tiempos difíciles tú sabe, y cuando apareció ahí en el cordel me lo puse de nuevo. De un día para otro me empezó una cosa, me sentí mal y en el médico me dijeron: Myriam esto es malo ${ }^{16}$. Yo me tiré a morir, y ella feliz me decía: "no te preocupes que desde Italia yo te mando la estilla [dinero] y no te falta nada, pero no podemos dejar escapar al yuma, si ya tú no puedes me voy yo...", y además me decía: "no vayas a los curanderos que las cosas de Dios no se pueden evitar". La suerte fue que un día la viejita Ambrosia venía cargada de jabas ${ }^{17}$, y se sentó a descansar en mi casa, y me dice: "perdona hija no sé si tú crees, pero a ti te han hecho un daño"; y ahí bueno a correr y a hacer todos los remedios.

Ambrosia Agramonte explicó además que ella y su madre, en medio de los hechos, querían devolver el "daño" a la prima, pero que les aconsejó no revolver eso, "dejárselo a Dios". No obstante, por insistencia de la madre, ellas se fueron donde otro curandero para vengarse, pues aquella [la prima] no podía

\footnotetext{
16 Se refiere al cáncer.

17 Bolsas con alimentos.
} 
salirse con suya. Myriam comenta que ella sí fue "por no irle a la contraria a mami, que se pone de madre" ${ }^{18}$

Contraria a la aspiración de Lagarde (2012, 2005, 1992) sobre la sororidad femenina, la sexualidad permite ver esa supresión de lo común entre mujeres primando las distancias y las competencias por la relación con los hombres, y la autoridad. Ante esta propuesta feminista, la enemistad genérica constituye una de las armas del patriarcado para garantizar su propia reproducción. En especial ello ocurre en contextos de supervivencia.

Tales disputas no solo implican sobrevivir, sino que se prefiguran como escaños para el ascenso en la estratificación sexual y social: las jineteras aspiraban a ascender socialmente mediante su labor sexual y luego blanquear su posición social. Como es el caso actual de Myriam, quien reside en Italia, y opina: “cuando la gente te ve llegar con fulas [dólares] a Cuba ya se olvida de que fuiste jinetera" (Myriam 2017, conversación por chat).

Al concluir esta parte de la argumentación debo decir que las relaciones sexogenéricas de poder entre mujeres dan cuenta de una enemistad genérica femenina más que de redes de solidaridad o construcciones de sororidad. Tal enemistad se puede medir en las jerarquías y competencias/disputas donde los hombres se convierten en objetos -alterando la teoría bourdieuana de la economía de los bienes simbólicos se observa en las oposiciones entre jineteras, o jineteras-esposas extranjeras-. Tal proceder les permiten a las mujeres aumentar su capital simbólico y ascender socialmente en contextos de crisis. La

${ }^{18}$ Frase coloquial que denota autoridad y significa ponerse fuerte, exigente. 
jerarquía se torna un elemento importante ya que con base en las relaciones familiares inicia con la autoridad maternal y se incrementa con la edad.

\section{LA BRUJERÍA SEXUAL, ¿ENTRE DOMINADOS, DOMINADORAS Y ENEMIGAS?: REFLEXIONES FINALES}

La brujería sexual opera dentro de las relaciones de poder sexogenéricas a mediados del periodo especial en Mayajigua, al centro norte de Cuba, en tres sentidos fundamentales. Primero, como arma ante la dominación masculina que compensa el cambiante equilibrio de poder entre los sexos dentro de la relación marital, sobre la base de las costumbres y las leyes del orden social. Segundo, integra las relaciones de poder entre mujeres dejando en claro la enemistad genérica femenina como recurso que favorece la reproducción del patriarcado; y tercero crea jerarquías sexuales y sociales que se entrecruzan con otras categorías naturalizadas de desigualdad.

La brujería sexual funciona nivelando aquella forma de dominación "legítima" contenida en la virilidad: la procreación. A su vez, establece la asimilación de la dominación como un proceso anclado en las costumbres y que se manifiesta como un fenómeno autoaprehendido tanto por las mujeres como por los hombres. Asimismo, vale la pena reevaluar la economía de los bienes simbólicos para entender cómo cambian las nociones de capital y objeto -en el sentido bourdieuano- al analizarlas en contextos particulares, como sostienen, aunque en formas distintas, Stolcke (2000) y Elias (1994).

Al imbricar los trabajos de Bourdieu (2000), Stolcke (2000), Elias (1994) y Rubin (1989) se puede analizar la dominación masculina en vínculo con el matrimonio y la familia como unidades microsociales, y entender la asimilación de la dominación masculina dentro de la formación de costumbres. Del mismo modo se pueden ver las interconexiones sociales (Elias, 1994), entrelazadas con las 
jerarquías sexuales y sociales (Rubin, 1989). Sin embargo, las relaciones de poder sexogenéricas entre mujeres constituye un aspecto donde tales autores no se adentraron, por eso me he apoyado en el trabajo de Marcela Lagarde para construir una explicación al respecto.

En este particular se concluye que, en lugar de establecer redes solidarias, prima entre las mujeres una enemistad con base en lo sexogenérico que se explica en las competencias por los hombres y en la autoridad femenina. Invirtiendo la apreciación de Bourdieu (2000) se consideran los hombres como objetos capaces de incrementar el capital de las mujeres en disputa. El otro componente se resuelve al revisar las jerarquías de las mujeres en las relaciones de parentesco que, si bien reproducen las tradicionales formas de asimilación de la dominación, crean formas de poder desde la autoridad. ${ }^{19}$

Si la jerarquía social es una ecuación que integra la clase, la raza y el sexo/género como elementos esenciales, y en medio del periodo especial en Cuba, la clase, funciona como constante, -no porque no varía, sino porque su variación no implica un cambio importante ante la crisis nacional-, entonces el componente sexogenérico en relación con la raza toma mayor peso. “Debido a que la sexualidad es un nexo de las relaciones entre los géneros, una parte importante de la opresión de las mujeres está contenida en y mediada por la sexualidad" (Rubin, 1989, p. 44). Entonces se pueden pensar las relaciones de poder sexogenéricas no solo desde la opresión hombre-mujeres, sino entre las propias mujeres y como variable de la estratificación social.

Este acercamiento permite reflexionar sobre el convulso contexto del periodo especial en Cuba. En ese aspecto, se visibilizan las formas en que se organiza la

${ }^{19}$ Este análisis pudiera extenderse a la relación jefas-subordinadas. 
desigualdad en el orden social, tomando como referentes al género, la sexualidad y la raza. Asimismo, informa de cómo se generan modos de supervivencia en etapas de crisis y las maneras en que interactúan estos con la economía sumergida [desde el mercado informal] y la movilidad social.

Este esfuerzo se ha concentrado en revisar los supuestos teóricos con base en los casos presentados y tomando como foco de análisis a la brujería sexual. De este modo aparecen nuevos significados tanto de la dominación masculina como de las relaciones de poder entre mujeres, las jerarquías sociales y el propio contexto de análisis. Así, estas realidades ofrecen distintos horizontes de interpretación, con la sexualidad como campo de estudio.

Se asumen aquí los retos propuestos por Rubin (1989) y Stolcke (2000). La primera convida a teorizar radicalmente sobre el sexo y la sexualidad; mientras que la segunda advierte de las dificultades conceptuales de las feministas al distinguir sexo y género, desnaturalizando cuáles diferencias resultan inevitables, construidas o impuestas (Stolcke, 2000). Ante ello, el análisis arroja dos lecciones metodológicas importantes: por una parte, resulta oportuno ver lo sexogenérico como sistema y en perspectiva relacional, y por otra, ubicar esta relación en un entramado complejo de interconexiones (Elias, 1994).

Ha sido esta una aproximación reflexiva al fenómeno de la brujería sexual en Cuba a mediados del periodo especial como parte de las relaciones sexogenéricas de poder desde los hombres y también entre mujeres. Todo ello en un intento analítico para desentramar sociológicamente lo qué esconde esa “burundanga en el café" y por qué la gente en Mayajigua, al centro norte de Cuba, sigue "profesando y echando bilongo". 


\section{BIBLIOGRAFÍA}

Banco Central de Cuba. S.f. “El periodo especial: la economía cubana en la década de los años 90" y “Desarrollo del país por actividades económicas", 6-59. $\begin{array}{llll}\text { Consultado en } & \text { agosto }\end{array}$ https: / / www.bc.gob.cu/Anteriores / Otros / economia\%20cubana.pdf

Basail Rodríguez, A. y M. Y. Castañeda Seijas. (1999). Conflictos y cambios de identidad religiosa en Cuba. Convergencia. Revista de Ciencias Sociales, 6, 20, 173-194.

Behar, R. (1993). Brujería sexual, colonialismo y poderes de las mujeres: su reflejo en los archivos de la Inquisición Mexicana. En V. Stolcke (comp.), Mujeres invadidas. La sangre de la Conquista de América, (171-199). Madrid: Horas y Horas.

Bolívar, N. (1997). El legado africano en Cuba. Papers. Revista de sociología, 52, 155-166. http://dx.doi.org/10.5565/rev/papers.1886

Bourdieu, P. (2000). Imagen aumentada. En La dominación masculina, (17-72). Barcelona: Anagrama.

Cárdenas Molina, G., y Tristá Pérez, A. M. (2000). Diccionario del español de Cuba. Madrid: Gredos.

Constitución, Cuba. (1992). Constitución de la República de Cuba. Gaceta Oficial de la República de Cuba.

De la Fuente, A. (2001). Una nación para todos: raza, desigualdad y política en Cuba, 19002000. Madrid: Editorial Colibrí.

Elias, N. (1994). "El cambiante equilibrio de poder entre los sexos". En Norbert Elias, Conocimiento y poder (pp. 121-166). Madrid: La Piqueta.

Espina, M. P. (1997). Transformaciones recientes de la estructura socioclasista cubana. Papers 52, 83-99.

Espina, M. P. (2008). Viejas y nuevas desigualdades en Cuba: Ambivalencias y perspectivas de la reestratificación social. Nueva Sociedad, 216, 133-149.

Espina, M.; Rodríguez, J. L.; Triana, J. y R. Hernández. (2011). “El Período especial veinte años después". Temas 65, enero-marzo, 59-75.

Lagarde, M. (1992). Enemistad y sororidad: hacia una nueva cultura feminista. Memoria, 28, 24-46, México: Centro de Estudios del Movimiento Obrero y Socialista. 
Lagarde, M. (2005). Para mis socias de la vida: claves--el poderío y la autonomía de las mujeres, feministas--los liderazgos entrañables, para--las negociaciones en el amor (Vol. 48). Madrid: Horas y horas.

Lagarde, M. (2012). El feminismo en mi vida: Hitos, claves y topías. México: Gobierno de la Ciudad de México, Instituto de las Mujeres del Distrito Federal.

ONE (Oficina Nacional de Estadísticas e Información. República de Cuba). (2010). Encuesta Nacional de Fecundidad 2009, Resultados. Consultado el 26 de julio de

2017.

http:/ / www.one.cu/publicaciones/cepde/enf/Completa/Resultados.pdf

Ortiz, F. (1940). Del fenómeno social de la transculturación y de su importancia en Cuba. Revista Bimestre Cubana, 46, 273-278.

Pérez-López, J., \& Murillo S., L. (2003). El interminable periodo especial de la economía cubana. Foro Internacional, 43 (3 (173)), 566-590. www.jstor.org/stable/27739198

Rubin, G. (1989). “Reflexionando sobre el sexo: notas para una teoría radical de la sexualidad": En Carole Vance (comp.), Placer y peligro. Explorando la sexualidad femenina, (pp. 113-190). Madrid: Revolución.

Safa, H. (2012). "Class, Gender, and Race in the Caribbean: Reflections on an Intellectual". Journey Canadian Journal of Latin American and Caribbean Studies, $37,74,219-242$.

Sklodowska, E. (2016). Invento, luego resisto: el período especial en Cuba como experiencia y metáfora (1990-2015). Cuarto propio: Santiago de Chile.

Stolke, V. (2000). ¿Es el sexo para el género lo que la raza para la etnicidad... y la naturaleza para la sociedad? Revista Política y Cultura, 14, 25-60. 